\title{
The Incidence of Shoulder Injury among Collegiate Overhead Athletes
}

\author{
Kevin Laudner \\ Illinois State University \\ Rob Sipes \\ Eastern Illinois University
}

\begin{abstract}
Shoulder injury in overhead athletes, who perform repetitive overhead motions, has been well documented; however, there is a paucity of data regarding the incidence of specific shoulder injuries in these individuals. Data were collected from the preseason medical examinations and medical records maintained throughout the collegiate careers of 371 overhead athletes. Shoulder injuries were documented in $30 \%$ of the athletes during their athletic careers. Subacromial impingement syndrome and rotator cuff (RTC) tendonitis were the most common shoulder injuries for each individual sport and accounted for $27 \%$ and $24 \%$ of the total shoulder injuries respectively. These injuries had a significantly higher incidence rate $(p=.001)$ than any other injury among the athletes. Significant incidence rates were found for baseball players diagnosed with subacromial impingement $(p=.001)$, softball players diagnosed with subacromial impingement and RTC tendonitis $(p=.001)$, swimmers diagnosed with subacromial impingement, RTC tendonitis, and biceps tendonitis $(p=.001)$, and tennis players diagnosed with subacromial impingement and RTC tendonitis $(p=.001)$. No significant incidence rates were found for the number of injured athletes per sport $(p=.42)$ or for the total number of injuries per sport $(p=.11)$. Rotator cuff tendonitis and subacromial impingement syndrome were the most common shoulder injuries reported for each of the five sports.
\end{abstract}

There are more than 157,000 student-athletes competing in NCAA Division I intercollegiate athletics with over 33,000 of these athletes participating in overhead sports, which require repetitive overhead motions, such as baseball, softball, swimming, tennis, and volleyball (2004-2005 National Collegiate Athletic Association Sports Sponsorship and Participation Rates Report, 2006). Motions such as throwing (Andrews \& Fleisig, 1998; Barrentine, Fleisig, Whiteside, Escamilla, \&

Laudner is with Illinois State University, Kinesiology and Recreation, Normal, IL 61790. Sipes is with Eastern Illinois University, Kinesiology and Sport Studies, Charleston, IL. 
Andrews, 1998; Bigliani et al., 1997; Borsa, Dover, Wilk, \& Reinold, 2006; Borsa, Wilk et al., 2005), serving (Ellenbecker, Roetert, Bailie, Davies, \& Brown, 2002; van der Hoeven \& Kibler, 2006), and spiking a ball (Baltaci \& Tunay, 2004), as well as the overhead swimming stroke (Bak \& Magnusson, 1997; Borsa, Scibek, Jacobson, \& Meister, 2005) require a high level of shoulder mobility and stability to participate at a competitive level and prevent injury. Due to the highly repetitive motions, large forces, and use of arms in landings from forward dives, shoulder injury is a common occurrence among these athletes (2004-2005 National Collegiate Athletic Association Injury Surveillance System, 2006). These overhead motions place large amounts of force and strain on both the static and dynamic restraints of the shoulder and over time are believed to result in micro trauma. This micro trauma may result in deficient functional shoulder stability and an increased susceptibility to decreased athletic performance and shoulder injury (Jobe, Kvitne, \& Giangarra, 1989; Paley, Jobe, Pink, Kvitne, \& ElAttrache, 2000).

Despite the advances in diagnostic and treatment interventions, shoulder injury continues to plague overhead athletes and the clinicians that treat such injuries. Although there has been an extensive amount of research investigating the kinematics, kinetics, and pathomechanics of overhead athletic motions, such as throwing, swimming, the tennis serve, and volleyball spike, little data are available regarding the incidence of shoulder injuries among these overhead athletes.

Reporting the incidence of specific shoulder injuries among various overhead athletes may allow clinicians advanced knowledge in the prevention and treatment of such injuries, thereby decreasing the time lost from competition. Therefore, the purpose of this study was to determine the incidence of shoulder injuries among NCAA Division I overhead athletes and to determine the types of shoulder injuries most common among specific overhead sports, such as swimming, baseball, softball, tennis, and volleyball.

\section{Methods}

\section{Subjects}

Data were collected from the preseason medical examinations and from the medical records maintained throughout the collegiate careers of 371 male and female (male $=152$, female $=219$ ) overhead athletes. Inclusion criteria consisted of athletes who participated in baseball, softball, women's swimming, men's and women's tennis, and women's volleyball at the NCAA Division I level. Exclusion criteria consisted of any injury that was not documented by an allied health care professional or those injuries reported to have been caused by a non sport-related event.

\section{Procedures}

Records were reviewed retrospectively in accordance with the university's institutional review board. Potential subjects were screened from the baseball, softball, women's swimming, men's and women's tennis, and women's volleyball teams at Illinois State University during the 2000-2006 athletic seasons. 
Medical records consisted of team physician diagnoses, athletic trainer and physical therapist examinations and records, and diagnostic tests used for confirmation of specific diagnosis (e.g., radiograph, MRI, CT, special tests, flexibility tests, strength tests). Information collected consisted of sport participating in at time of injury and diagnosis of injury. Specific surgical procedures, rehabilitation protocols, and time lost from competition were not collected for this investigation.

An injury was defined as physical trauma to an athlete's shoulder in which medical treatment was sought from an allied health care professional. This definition allowed for traumatic injuries that may have required time lost from competition, as well as chronic injuries that may have been treated on a day-to-day basis without missing any practices or games. Shoulder injuries were categorized into one of the following groups: periscapular strain, subacromial impingement syndrome, superior labrum anterior to posterior (SLAP) lesion, RTC tendonitis, biceps tendonitis, anterior instability, multidirectional instability, acromioclavicular (AC) injury, and pectoralis major strain.

We used the Statistical Package for the Social Sciences (version 14.0; SPSS Inc, Chicago, IL) to analyze the data. A chi-square $\left(X^{2}\right)$, goodness of fit test was used to identify any associations among number of injuries, types of shoulder injury, and number of injured athletes per sport. These findings were considered significant at an alpha level of $p<.05$.

\section{Results}

A total of 371 athletes were investigated (Table 1). Shoulder injuries were documented in $30 \%$ of the intercollegiate overhead athletes at some point during their athletic careers with volleyball players experiencing the highest incidence of shoulder injuries among the five sports (Figure 1). A total of 140 discrete shoulder injuries were documented among 112 athletes complaining of shoulder related pain, indicating a $25 \%$ chance of subsequent shoulder injury (Table 1).

\section{Table 1 Incidence of Shoulder Injuries per Sport}

\begin{tabular}{lcccccc}
\hline Injury & Baseball & Softball & Swimming & Tennis & Volleyball & Totals \\
\hline Players & 126 & 55 & 104 & 51 & 35 & 371 \\
Injured Players & 41 & 17 & 24 & 15 & 15 & 112 \\
Injuries & 48 & 19 & 32 & 19 & 22 & 140 \\
\hline
\end{tabular}




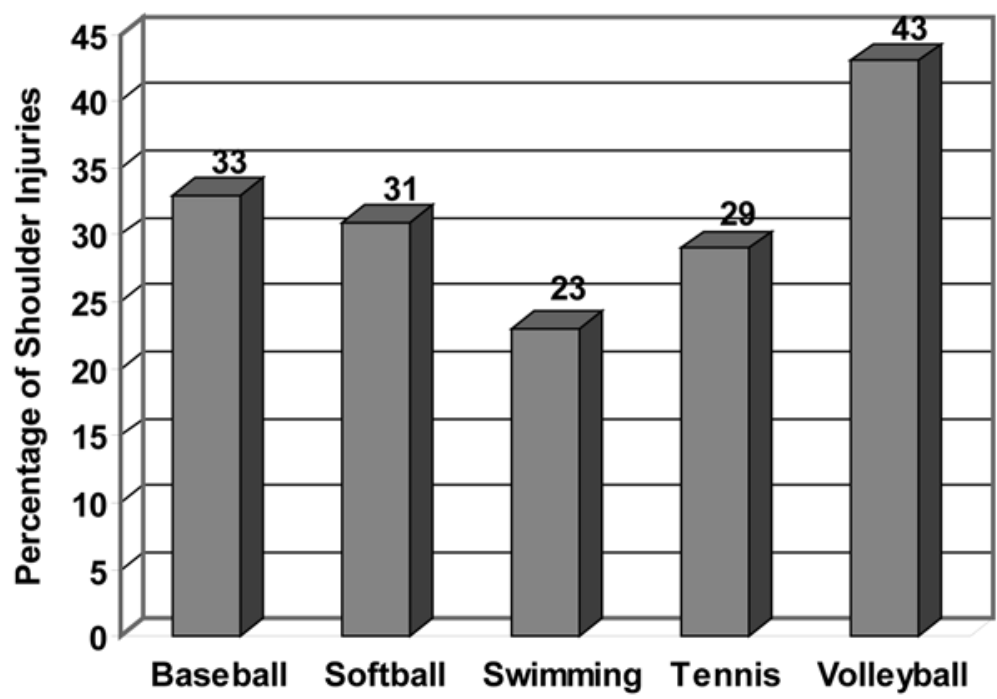

Figure 1 - Incidence of athletes with reported shoulder injuries per sport.

Subacromial impingement syndrome and RTC tendonitis accounted for $27 \%$ and $24 \%$ of the total shoulder injuries respectively and had significantly higher incidence rates compared with any other injury $\left(p=.001, X^{2}=101.3\right.$; Table 2$)$. Significantly higher incidence rates were found for baseball players diagnosed with subacromial impingement $\left(p=.001, X^{2}=28.3\right)$, softball players diagnosed with subacromial impingement and RTC tendonitis $\left(p=.001, X^{2}=29.9\right)$, swimmers diagnosed with subacromial impingement, RTC tendonitis, and biceps tendonitis $\left(p=.001, X^{2}=30.5\right)$, and tennis players diagnosed with subacromial impingement and RTC tendonitis ( $p=.001, X^{2}=35.2$; Table 3$)$. No significant differences were reported for the incidence rates of shoulder disorder among volleyball players $(p$ $=.18, X^{2}=12.5$; Table 3).

No significant differences were found for any specific shoulder injury among sports. However, AC injuries had an expected frequency less than 1.0 (.7) among volleyball players, therefore an appropriate distribution could not be created. Furthermore, no significance was found for the number of injured athletes per sport $(p=$ $.4, X^{2}=3.9$; Figure 1) or for the total number of injuries per sport $\left(p=.1, X^{2}=7.3\right)$. 
Table 2 Incidence of Common Shoulder Injuries

\begin{tabular}{lcc}
\hline Shoulder Injury & n & Percent of Total Shoulder Injuries \\
\hline Subacromial Impingement* $^{*}$ & 38 & 27.1 \\
Rotator Cuff Tendonitis* $_{\text {Biceps Tendonitis }}$ & 34 & 24.3 \\
Periscapular Strain & 17 & 12.1 \\
SLAP Lesion & 13 & 9.3 \\
Anterior Instability & 11 & 7.9 \\
Acromioclavicular injury & 11 & 7.9 \\
Multi-Directional Instability & 10 & 7.1 \\
Pectoralis Major Strain & 4 & 2.9 \\
\hline
\end{tabular}

SLAP $=$ superior labral anterior to posterior

*Statistically significant incidence at $P<.05$

Table 3 Incidence of Common Shoulder Injuries per Sport

\begin{tabular}{|c|c|c|c|c|c|c|c|c|c|c|}
\hline \multirow[t]{2}{*}{ Injury } & \multicolumn{2}{|c|}{ Baseball } & \multicolumn{2}{|c|}{ Softball } & \multicolumn{2}{|c|}{ Swimming } & \multicolumn{2}{|c|}{ Tennis } & \multicolumn{2}{|c|}{ Volleybal } \\
\hline & $\mathbf{n}$ & $\%$ & $\mathbf{n}$ & $\%$ & $\mathbf{n}$ & $\%$ & $\mathbf{n}$ & $\%$ & & $\%$ \\
\hline Periscapular Strain & 4 & 8 & 2 & 11 & 3 & 9 & 3 & 16 & 1 & 5 \\
\hline SAIS & $12 *$ & 25 & $6^{*}$ & 32 & $8^{*}$ & 25 & $8^{*}$ & 42 & 4 & 18 \\
\hline SLAP Lesion & 7 & 15 & 1 & 5 & 2 & 6 & 0 & & 1 & 5 \\
\hline RTC Tendonitis & 9 & 19 & $7 *$ & 37 & $8 *$ & 25 & $5^{*}$ & 26 & 5 & 23 \\
\hline Biceps Tendonitis & 3 & 6 & 1 & 5 & $7 *$ & 22 & 2 & 11 & 4 & 18 \\
\hline Anterior Instability & 7 & 15 & 1 & 5 & 0 & & 1 & 5 & 2 & 9 \\
\hline MD Instability & 0 & & 1 & 5 & 3 & 9 & 0 & & 0 & \\
\hline AC Injury & 5 & 10 & 0 & & 0 & & 0 & & 5 & 10 \\
\hline $\begin{array}{l}\text { Pectoralis Major } \\
\text { Strain }\end{array}$ & 1 & 2 & 0 & & 1 & 3 & 0 & & 0 & \\
\hline Totals & 48 & & 19 & & 32 & & 19 & & 22 & \\
\hline$X 2$ & 28.3 & & 29.9 & & 30.5 & & 35.2 & & 12.5 & \\
\hline$P$ Value & .001 & & .001 & & .001 & & .001 & & .18 & \\
\hline
\end{tabular}

SAIS = subacromial impingement syndrome; $\mathrm{RTC}=$ rotator cuff $; \mathrm{MD}=$ multidirectional $; \mathrm{AC}=$ acromioclavicular

*Statistically significant incidence at $P<.05$ 


\section{Discussion}

For motions such as the tennis serve, overhead throw, and volleyball spike, the high rotational forces experienced by the shoulder during the acceleration and deceleration phases of the movements place the soft tissue structures at risk for microtrauma and an ensuing injury (Baltaci \& Tunay, 2004; Burkhart, Morgan, \& Kibler, 2003; Kibler, 1998). Although, the swimming motion doesn't produce such drastic acceleration and deceleration forces, the repetitive overhead motions and subsequent periscapular and RTC fatigue place the shoulder in similarly vulnerable positions to that of the more ballistic athletic movements (Bak \& Magnusson, 1997; Borsa, Scibek et al., 2005). As such, overuse injuries have been extensively reported among athletes participating in such sports (Laudner, Myers, Pasquale, Bradley, \& Lephart, 2006; Myers, Laudner, Pasquale, Bradley, \& Lephart, 2006; Paley et al., 2000; Safran, Borsa, Lephart, Fu, \& Warner, 2001; Su, Johnson, Gracely, \& Karduna, 2004; Tibone et al., 1985; van der Hoeven \& Kibler, 2006; Yanai \& Hay, 2000). The results of this study support those previous reports and emphasize the most common injuries among swimmers, volleyball, baseball, softball, and tennis players.

Our results showed that subacromial impingement syndrome had significantly higher incidence rates in four of the five sports. Rotator cuff tendonitis had significantly higher incidence rates among three of the five sports. As athletes transition from seasonal high school sports to the year round training and competitions of collegiate athletics, such athletes may be at an increased risk for the development of these chronic shoulder injuries. Factors such as soft tissue contracture,(Burkhart et al., 2003; Myers et al., 2006; Tyler, Nicholas, Roy, \& Gleim, 2000) muscle weakness (Bak \& Magnusson, 1997; Baltaci \& Tunay, 2004; Donatelli et al., 2000), altered neuromuscular coordination (DiGiovine, Jobe, Pink, \& Perry, 1992; Glousman, 1993; Gowan, Jobe, Tibone, Perry, \& Moynes, 1987), and bony and postural abnormalities (Ludewig \& Cook, 1996; Riand, Levigne, Renaud, \& Walch, 1998) are common among overhead athletes and have been associated with these chronic shoulder injuries. Furthermore, a history of injury has been indicated to increase an athlete's risk of subsequent injury (Kaplan, Flanigan, Norwig, Jost, \& Bradley, 2005; Turbeville, Cowan, Owen, Asal, \& Anderson, 2003). This finding is further supported by our results, which showed that $25 \%$ of the injured athletes sustained a subsequent injury.

Based on our results, various prevention techniques should be considered by the clinician to decrease the risk of shoulder injury, especially subacromial impingement syndrome and RTC tendonitis, in the overhead athlete. Techniques such as lengthening of the posterior shoulder soft tissue (Burkhart et al., 2003; Wilk, Meister, \& Andrews, 2002), as well as RTC and periscapular strengthening (Burkhart et al., 2003; Cordasco, Wolfe, Wootten, \& Bigliani, 1996; Lear \& Gross, 1998; Moseley, Jobe, Pink, Perry, \& Tibone, 1992; Myers et al., 2005; Uhl, Carver, Mattacola, Mair, \& Nitz, 2003) may be incorporated in an attempt to decrease these incidence rates. Stretching and strengthening of the shoulder soft tissue are hypothesized to increase the congruency between humeral and scapular motion, thus improving the efficiency of the shoulder articulations by decreasing stress on static restraints and increasing the efficiency in the dynamic stabilizers, as well as improving athletic performance (Burkhart et al., 2003; Kibler, 1998). 
Although our results indicated a high incidence rate in the total number of shoulder injuries among volleyball athletes, neither subacromial impingement syndrome nor RTC tendonitis were found to have a significantly higher incidence rate than any of the other common shoulder disorders. This finding was surprising considering the significantly higher incidence rates of one or both of these two chronic conditions among the other four sports. As such, the lack of significance may have been due to the large number of acute injuries, specifically AC injury $(n=5)$, reported in volleyball players. Each of these injuries was reportedly sustained due to the traumatic impacts placed on the shoulder during a diving motion. Although, dives may be somewhat common in baseball, softball, and even tennis, they appear to be much more evident and necessary during a volleyball match. As these athletes routinely dive in a head-first fashion to prevent the volleyball from contacting the ground, injury may occur from either direct or in-direct forces distributed to the AC articulation.

When evaluating the results of the current study, the authors note several limitations that warrant acknowledgment. The exact mechanism of injury was not recorded among all injuries and thus makes determining the relationship between the sport specific movement and injury difficult. Similarly, the playing time of each athlete was not reported making comparison between the different injuries to exposure rates arduous. The experience of the various clinicians performing the examination where not determined and may have lead to misclassification of some injuries. However, all clinicians involved with this study were allied health care professionals (e.g., athletic trainer, medical doctor, physical therapist) who have been trained in the examination and diagnosis of orthopedic related injuries. Furthermore, some shoulder diagnoses, such as subacromial impingement syndrome and RTC tendonitis, may overlap so that an athlete may have more than one diagnosis. However, this factor was limited due to positive diagnostic and special tests indicated by the diagnosing clinician to isolate the specific injury. Next, these data were collected from athletes at one NCAA institution. However, there were no extraneous circumstances that would lead the authors to believe that these data cannot be generalized to athletes at other NCAA institutions. Lastly, athletes may have been biased to suppress injury information in an attempt to improve their status among the team. Thus, some injuries may not have been completely accounted for during this study.

\section{Clinical Implications}

Our results indicate that subacromial impingement syndrome is more common among swimmers, baseball, softball, and tennis players. Rotator cuff tendonitis was found to be more prevalent among swimmers, softball and tennis players. And biceps tendonitis was more prevalent among swimmers. Furthermore, athletes with a history of shoulder injury were inclined to subsequent shoulder injury. Our results emphasize the need for prevention techniques to decrease the incidence of chronic shoulder injuries among overhead athletes with particular measures targeting prevention of subacromial impingement syndrome and RTC tendonitis. Early detection of such injuries may lead to decreased periods of time lost from competition, costly medical bills, and possible need for surgical intervention. 


\section{References}

(2006). 2004-2005 National Collegiate Athletic Association Injury Surveillance System. Indianapolis, IN: National Collegiate Athletic Association.

(2006). 2004-2005 National Collegiate Athletic Association Sports Sponsorship and Participation Rates Report. Indianapolis, IN: National Collegiate Athletic Association.

Andrews, J.R., \& Fleisig, G.S. (1998). Preventing throwing injuries. The Journal of Orthopaedic and Sports Physical Therapy, 27(3), 187-188.

Bak, K., \& Magnusson, S.P. (1997). Shoulder strength and range of motion in symptomatic and pain-free elite swimmers. American Journal of Sports Medicine, 25(4), 454-459.

Baltaci, G., \& Tunay, V.B. (2004). Isokinetic performance at diagonal pattern and shoulder mobility in elite overhead athletes. Scandinavian Journal of Medicine \& Science in Sports, 14(4), 231-238.

Barrentine, S.W., Fleisig, G.S., Whiteside, J.A., Escamilla, R.F., \& Andrews, J.R. (1998). Biomechanics of windmill softball pitching with implications about injury mechanisms at the shoulder and elbow. The Journal of Orthopaedic and Sports Physical Therapy, 28(6), 405-415.

Bigliani, L.U., Codd, T.P., Connor, P.M., Levine, W.N., Littlefield, M.A., \& Hershon, S.J. (1997). Shoulder motion and laxity in the professional baseball player. American Journal of Sports Medicine, 25(5), 609-613.

Borsa, P.A., Dover, G.C., Wilk, K.E., \& Reinold, M.M. (2006). Glenohumeral range of motion and stiffness in professional baseball pitchers. Medicine and Science in Sports and Exercise, 38(1), 21-26.

Borsa, P.A., Scibek, J.S., Jacobson, J.A., \& Meister, K. (2005). Sonographic stress measurement of glenohumeral joint laxity in collegiate swimmers and age-matched controls. American Journal of Sports Medicine, 33(7), 1077-1084.

Borsa, P.A., Wilk, K.E., Jacobson, J.A., Scibek, J.S., Dover, G.C., Reinold, M.M., et al. (2005). Correlation of range of motion and glenohumeral translation in professional baseball pitchers. American Journal of Sports Medicine, 33(9), 1392-1399.

Burkhart, S.S., Morgan, C.D., \& Kibler, W.B. (2003). The disabled throwing shoulder: Spectrum of pathology part III: The SICK scapula, scapular dyskinesis, the kinetic chain, and rehabilitation. Arthroscopy, 19(6), 641-661.

Cordasco, F.A., Wolfe, I.N., Wootten, M.E., \& Bigliani, L.U. (1996). An electromyographic analysis of the shoulder during a medicine ball rehabilitation program. American Journal of Sports Medicine, 24(3), 386-392.

DiGiovine, N.M., Jobe, F.W., Pink, M., \& Perry, J. (1992). An electromyographic analysis of the upper extremity in pitching. Journal of Shoulder and Elbow Surgery, 1(1), 15-25.

Donatelli, R., Ellenbecker, T.S., Ekedahl, S.R., Wilkes, J.S., Kocher, K., \& Adam, J. (2000). Assessment of shoulder strength in professional baseball pitchers. The Journal of Orthopaedic and Sports Physical Therapy, 30(9), 544-551.

Ellenbecker, T.S., Roetert, E.P., Bailie, D.S., Davies, G.J., \& Brown, S.W. (2002). Glenohumeral joint total rotation range of motion in elite tennis players and baseball pitchers. Medicine and Science in Sports and Exercise, 34(12), 2052-2056.

Glousman, R. (1993). Electromyographic analysis and its role in the athletic shoulder. Clinical Orthopaedics and Related Research, 288, 27-34.

Gowan, I.D., Jobe, F.W., Tibone, J.E., Perry, J., \& Moynes, D.R. (1987). A comparative electromyographic analysis of the shoulder during pitching. Professional versus amateur pitchers. American Journal of Sports Medicine, 15(6), 586-590.

Jobe, F.W., Kvitne, R.S., \& Giangarra, C.E. (1989). Shoulder pain in the overhand or throwing athlete. The relationship of anterior instability and rotator cuff impingement. Orthopaedic Review, 18(9), 963-975. 
Kaplan, L.D., Flanigan, D.C., Norwig, J., Jost, P., \& Bradley, J. (2005). Prevalence and variance of shoulder injuries in elite collegiate football players. American Journal of Sports Medicine, 33(8), 1142-1146.

Kibler, W.B. (1998). The role of the scapula in athletic shoulder function. American Journal of Sports Medicine, 26(2), 325-337.

Laudner, K.G., Myers, J.B., Pasquale, M.R., Bradley, J.P., \& Lephart, S.M. (2006). Scapular dysfunction in throwers with pathologic internal impingement. The Journal of Orthopaedic and Sports Physical Therapy, 36(7), 485-494.

Lear, L.J., \& Gross, M.T. (1998). An electromyographical analysis of the scapular stabilizing synergists during a push-up progression. The Journal of Orthopaedic and Sports Physical Therapy, 28(3), 146-157.

Ludewig, P.M., \& Cook, T.M. (1996). The Effect of Head Position on Scapular Orientation and Muscle Activity During Shoulder Elevation. Journal of Occupational Rehabilitation, 6(3), 147-158.

Moseley, J.B., Jr., Jobe, F.W., Pink, M., Perry, J., \& Tibone, J. (1992). EMG analysis of the scapular muscles during a shoulder rehabilitation program. American Journal of Sports Medicine, 20(2), 128-134.

Myers, J.B., Laudner, K.G., Pasquale, M.R., Bradley, J.P., \& Lephart, S.M. (2006). Glenohumeral range of motion deficits and posterior shoulder tightness in throwers with pathologic internal impingement. American Journal of Sports Medicine, 34(3), 385-391.

Myers, J.B., Pasquale, M.R., Laudner, K.G., Sell, T.C., Bradley, J.P., \& Lephart, S.M. (2005). On-the-Field Resistance-Tubing Exercises for Throwers: An Electromyographic Analysis. Journal of Athletic Training, 40(1), 15-22.

Paley, K.J., Jobe, F.W., Pink, M.M., Kvitne, R.S., \& ElAttrache, N.S. (2000). Arthroscopic findings in the overhand throwing athlete: evidence for posterior internal impingement of the rotator cuff. Arthroscopy, 16(1), 35-40.

Riand, N., Levigne, C., Renaud, E., \& Walch, G. (1998). Results of derotational humeral osteotomy in posterosuperior glenoid impingement. American Journal of Sports Medicine, 26(3), 453-459.

Safran, M.R., Borsa, P.A., Lephart, S.M., Fu, F.H., \& Warner, J.J. (2001). Shoulder proprioception in baseball pitchers. Journal of Shoulder and Elbow Surgery, 10(5), 438-444.

Su, K.P., Johnson, M.P., Gracely, E.J., \& Karduna, A.R. (2004). Scapular rotation in swimmers with and without impingement syndrome: practice effects. Medicine and Science in Sports and Exercise, 36(7), 1117-1123.

Tibone, J.E., Jobe, F.W., Kerlan, R.K., Carter, V.S., Shields, C.L., Lombardo, S.J., et al. (1985). Shoulder impingement syndrome in athletes treated by an anterior acromioplasty. Clinical Orthopaedics and Related Research, 198, 134-140.

Turbeville, S.D., Cowan, L.D., Owen, W.L., Asal, N.R., \& Anderson, M.A. (2003). Risk factors for injury in high school football players. American Journal of Sports Medicine, 31(6), 974-980.

Tyler, T.F., Nicholas, S.J., Roy, T., \& Gleim, G.W. (2000). Quantification of posterior capsule tightness and motion loss in patients with shoulder impingement. American Journal of Sports Medicine, 28(5), 668-673.

Uhl, T.L., Carver, T.J., Mattacola, C.G., Mair, S.D., \& Nitz, A.J. (2003). Shoulder musculature activation during upper extremity weight-bearing exercise. The Journal of Orthopaedic and Sports Physical Therapy, 33(3), 109-117.

van der Hoeven, H., \& Kibler, B. (2006). Shoulder Injuries in Tennis Players. British Journal of Sports Medicine, 40, 435-440.

Wilk, K.E., Meister, K., \& Andrews, J.R. (2002). Current concepts in the rehabilitation of the overhead throwing athlete. American Journal of Sports Medicine, 30(1), 136-151.

Yanai, T., \& Hay, J.G. (2000). Shoulder impingement in front-crawl swimming: II. Analysis of stroking technique. Medicine and Science in Sports and Exercise, 32(1), 30-40. 